\title{
Visualization and Problem-based Learning Approaches and Students' Attitude toward Learning Mathematics
}

\author{
Abera Abate $^{1 *}$ (D) Mulugeta Atnafu $^{1}$ (D), Kassa Michael ${ }^{1}$ (D) \\ ${ }^{1}$ Addis Ababa University, ETHIOPIA \\ *Corresponding Author: aberaabate32@gmail.com
}

Citation: Abate, A., Atnafu, M., \& Michael, K. (2022). Visualization and Problem-based Learning Approaches and Students' Attitude toward Learning Mathematics. Pedagogical Research, 7(2), em0119. https://doi.org/10.29333/pr/11725

\begin{abstract}
ARTICLE INFO
Received: 2 Oct. 2021

Accepted: 2 Feb. 2022

ABSTRACT

Mathematics is one of the important disciplines for students to solve day-to-day problems in life. Attitude towards mathematics and mathematics learning is critical for a better learning to happen. This study was conducted to investigate the effect of instructional approaches on attitudes of students towards mathematics learning. Quasiexperiment research was conducted in middle schools at Addis Ababa City Administration, Ethiopia to investigate the use of visualization techniques (VT), problem-based learning approach (PBLA), visualization techniquesassisted problem-based learning (VT-PBLA), and conventional instructional approach (CIA) as instructional approaches and their effect on students' attitude towards learning Mathematics. Four intact classes were selected of which the three were used as intervention groups named intervention group 1 (IG1), intervention group 2 (IG2) and intervention group 3 (IG3) each of which took specific instructional approach as an intervention and a comparison group (CG) that were assigned using simple random sampling techniques. The sample size used were $48,49,48$, and 47 students, respectively. Both pre and post-attitude Likert scale items were prepared and administered to the respondents before and after the intervention respectively. Paired samples t-test and ANCOVA were employed for analysis, and the results of the study show that the group taught with VT shown statistically significant difference on attitude and on each of the components of attitude, except for engagement. Moreover, the group taught with VT-PBLA also shown to have a statistically significant difference on attitude and their components except for engagement and confidence. PBLA alone did not show any significant mean difference in students' attitude towards learning mathematics and each of the components. The post-intervention comparison also showed significant mean difference between the groups for the overall attitude and the components of attitude except for engagement and confidence. These deviant findings seek further investigation to identify the possible causes or any possible amendments that could account to the instructional approaches.
\end{abstract}

Keywords: visualization techniques, problem-based learning approach, visualization techniques-assisted problem-based learning approach, attitude, mathematics

\section{INTRODUCTION}

The importance of mathematics has been addressed by studies such as (Astriani et al., 2017; Gregoire, 2016). Mathematics is an important issue that is related to an individual's success (Enu et al., 2015; Lipnevich et al., 2011). Mathematics as a subject is required for entry into many professions and it is important for existing as well as emerging occupations in a global economy that is recently based on information and technology. Saffer (1999) stated that mathematics is not only just useful in the day-to-day skills like managing money but also for the occupations that call the use of some mathematical skills. Consequently, mathematics is addressed at a higher rate compared to other subjects (Phonapichat et al., 2014), and it has been called as the queen of all sciences and a servant to all disciplines (Abe \& Gbenro, 2014; Ajayi et al., 2013). In line with this, mathematics provides knowledge and skills that are essential in the changing technological world for the $21^{\text {st }}$ century students (Ngussa \& Mbuti, 2017).

In Ethiopia, mathematics is one of the core and mandatory subjects to all students at all levels of schools. Yet, mathematics is seen as the most difficult subject in many parts of the world (Ignacio et al., 2006). In Ethiopia, the subject mathematics is viewed as difficult (NEAEA, 2016).

Student's proficiency of mathematics in schools is a reflective of the related variables including attitude towards mathematics and instructional approaches for effectively teaching the subject (Mazana et al., 2019). One of the ways that increase students' attitude is to arbitrate instruction through visualization techniques (VT) and problem-based learning approach (PBLA). These help students to develop their level of learning and promote some different styles of learning which support the attitude of students (Gangwer, 2015; Shatri \& Buza, 2017). Studies of Akinsola and Olowojaiye (2008), Beswick (2006), Mensah et al. (2013), and Syyeda (2016) suggest that students' attitude is associated with visualization techniques and problem-based learning approach and their 
integrated practices. Some studies indicate that there is a positive relationship among visualization techniques, problem-based learning approach, visualization techniques-assisted problem-based learning approach and students' attitude, and also there is a direct association between students' attitude and learning mathematics (Ruhan, 2007; Sirmaci, 2010; Uygun \& Tertemiz, 2014; Walker \& Lofton, 2003). Visualization techniques, problem-based learning approaches and visualization techniques-assisted problem-based learning approaches enhance students' attitude to learn mathematics and retention of subject matters of mathematics (Akinsola \& Animashun, 2007; Rabab'h \& Veloo, 2015; Ruhan, 2007; Walker \& Lofton, 2003). Despite these, students' own attitude is also considered to be an important factor.

Among the students' factors, attitude is regarded by many researchers as a key contributor to higher or lower performance in mathematics (Mata et al., 2012; Mohamed \& Waheed, 2011). Components of attitude towards mathematics such as confidence, usefulness, enjoyment and engagement have been examined (Pierce et al., 2007) and these are considered in this study.

Mathematics confidence refers to students' perceptions of their ability to achieve good results and their belief in their ability to deal with any difficulties in mathematics (Pierce et al., 2007). Students' confidence is an important factor that influences students' learning which in turn affects their performance in mathematics (Hannula et al., 2004). Students with high confidence believe in their abilities that they can be successful in learning mathematics. These students are ready to take mathematical challenges which in turn increase their academic performance. But students with low confidence do not believe in themselves, thus tend to avoid taking mathematical challenges (Adelson \& McCoach, 2011). Therefore, this leads into minimising the chances of expanding their mathematical skills and success. Hence, it is desirable to study the students' confidence and how it relates to their performance.

Usefulness of mathematics refers how much students value mathematics for their future and everyday life (Adelson \& McCoach, 2011). Finding mathematics useful tends to influence behavior related to mathematics performance. Particularly, those who find mathematics to be useful for their life put forth more effort in practicing mathematics (Pajares \& Miller, 1994; Syyeda, 2016). Even if students perceive their abilities in mathematics to be high, they may not engage in the task if they believe that it is of low value (Wigfield \& Eccles, 2000). Usefulness has been identified as a key variable in fostering positive attitudes toward mathematics (Guy et al., 2015).

Enjoyment of mathematics represents the extent to which a student, likes, enjoys and is interested in doing and learning mathematics (Ganley \& Lubienski, 2016; Kupari \& Nissinen, 2013). Students who perceived mathematics as enjoyable and interesting tend to spend more time and effort on mathematics and select more challenging mathematics problems (Stipek, 2002). Enjoyment might also be an indicator of motivation; those who find mathematics to be interesting and enjoyable tend to be more motivated to spend more time with practice and follow careers in mathematics (Seaton et al., 2014). Enjoyment affects both the degree and continuity of engagement in learning and the depth of understanding. Thus, it is important to consider this aspect of attitudes toward mathematics since students who believe they are good at mathematics might not pursue later mathematics activities if they do not like or enjoy the subject.

Engagement in mathematics is considered as students' involvement in the mathematical activity of the classroom and their commitment to learning the mathematical content. The term 'engagement' is viewed as different to 'participation', which here describes students choosing to enrol in the subject of mathematics (Sullivan \& McDonough, 2007). Thus, this study was conducted to better understand the relationship between selected instructional approaches used in the classroom, student' attitude, and learning mathematics.

\section{Statement of the Problem}

Ethiopian forth national learning assessment of grades 4 and 8 students conducted at the end of 2010/2011 indicated that students are unable to achieve the required competencies (NEAEA, 2013). According to this finding, the academic achievement of the students as measured by the mean score of the five subjects namely English, mathematics, biology, chemistry and physics was found to be less than the 50\% achievement level set by the Education and Training Policy of Ethiopia (TGE, 1994). Particularly, when looking at the mean score of mathematics for grade 4 (37.06\%) was below the minimum requirement (50\%). However, in grade 8 , the mean score of mathematics was still severely below the minimum requirement 50\% i.e. 25.5 (NEAEA, 2016). This low performance of students stems from lack of relating concepts of mathematics to daily life, ineffective instructional approach implemented in teaching and learning process and students' students' attitude to learn mathematics.

In line with this, studies point out instructional approaches like visualization and problem-based learning approach can facilitate not only the comprehension of mathematical concepts but also enhancing students' attitude towards mathematics (Eleftherios \& Theodosios, 2007). A paradigm shift regarding appropriate implementation of instructional approach is also believed to be vital to ensure a successful $21^{\text {st }}$ century classroom and to set up students for success in their future careers which in turn increases students' attitude toward mathematics (Akinsola \& Olowojaiye, 2008).

However, VT, PBLA, and VT-assisted PBLA might contribute to students' attitude toward learning mathematics, whose effect might be different from each other as adequate provision of required instructional approach facilities that are effectively utilize for instructional facilitation is important (Uygun \& Tertemiz, 2014). Thus, in this study, the researchers used visualization techniques, problem-based learning approach and visualization techniques-assisted problem-based learning approach to explore the effects on students' attitude towards learning mathematics.

\section{Objectives of the Study}

The objective of the study is to explore the effect of the use of visualization techniques, problem-based learning approach and visualization techniques-assisted problem-based learning approach on students' attitude. The following are the specific objectives of the study: 
1. To investigate whether there is a significant difference in students' attitude toward mathematics by using visualization techniques, problem-based learning approach and visualization techniques-assisted problem-based learning approaches

2. To examine the attitude and components of attitude of those students taught with visualization techniques, problembased learning approach and visualization techniques-assisted problem-based learning approach.

\section{Research Questions}

The study was guided by the following research questions:

1. Are there significant mean differences between pre-attitude and post- attitude, and the components of attitude of the intervention groups that use visualization techniques, problem-based learning approach and visualization techniquesassisted problem-based learning approach and the comparison group that use conventional instructional approach?

2. Are there significant mean differences between post-attitude and the components of attitude of the intervention groups that use visualization techniques, problem-based learning approach and visualization techniques-assisted problem-based learning approach and the comparison group that use conventional instructional approach when controlling the effect of pre-attitude and their components?

3. What are the effects of the instructional strategies of visualization techniques, problem-based learning approach and visualization techniques-assisted problem-based learning approach on students' attitude towards learning mathematics?

\section{METHODS OF THE STUDY}

\section{Research Design}

A quasi-experimental design is suitable for an experimental type research when it is not possible to employ random assignments (Creswell \& Plano Clark, 2011; Shadish et al., 2002). Since this study took intact classes without random assignment of the respondents, a quasi-experimental design was conducted to explore the effect of using visualization techniques, problembased learning approach and visualization techniques-assisted problem-based learning approach on students' attitude toward learning of mathematics. This happens when students are naturally organized in groups as classes within schools and are considered to share similar characteristics (Best \& Kahn, 2006).

\section{Sampling}

Among the middle schools found in Addis Ababa City Administration, four schools that have grades 7 and 8 were selected using purposive sampling for intervention. Those schools that were at similar condition in terms of school experience, teachers' qualification, and students' previous achievement were selected. So as to control for teacher variable, four teachers (one from each school) that are approximately equivalent to each other in terms of their experience and qualification were selected from the available teachers. After that, among the sections taught by the selected teachers, four sections (one from each of the schools) were selected through simple random sampling techniques and assigned as intervention group 1 (IG1), intervention group 2 (IG2), intervention group 3 (IG3), and comparison group (CG). The number of students involved in this study was 48, 49, 48, and 47, respectively.

\section{Data Collection Instrument}

The researchers adapted both pre- and post-attitude scales from the works of Martha (1996); and Tapia and Marsha (2004) with relevant edition for the attitude Likert scale to make them suitable for the specified grade level. The adapted attitude scale contained 32 items. The items were classified according to the main components of attitude namely students' confidence ( 8 items), usefulness of mathematics ( 8 items), enjoyment of mathematics ( 8 items), and engagement in mathematics ( 8 items) that emanate from the definitions provided in the above. The scale scored on a 1-5 Likert-type scale ranging from 1 (strongly disagree) to 5 (strongly agree). The respondents were asked to respond to each item. Halve of the statements in the scale are positive while the other half are negative. But during data entering into SPSS software the negative scores were reversed. Pre-attitude helps the researchers to know the level of students' attitude towards learning mathematics in general, whereas the post-attitude helps to know the students' attitude towards learning mathematics after implementation of the interventions. The instruments were reviewed by colleagues for content and face validity and these were pilot tested to estimate the reliability before the actual process of the data collection at a school that were not used as research area. The reliability of pre-attitude was 0.80 and post-attitude was 0.88 . The reliability of each of the components of pre-attitude and post-attitude were also in the acceptable range of reliability with alpha coefficient of more than 0.7 . Factor analysis was run and it confirmed the unidirectionality of the scales that assured. Therefore, the instruments were reliable to get appropriate data for the study.

\section{Activities During Lesson Periods}

The unit that covered in this study was geometric figures and measurement from grade seven and squares, square roots, cubes, and cube roots as well as further on working with variables from grade eight of mathematics syllabus in Ethiopia (MoE, 2011). After conducting the piloting. The three mathematics teachers who taught the intervention groups were given training on how to implement the intervention in the classroom. Although, pre-intervention scores are probable not meaningful, the instruments were administered to the students in the four groups as a pre- attitude to indicate if there were covariates between the groups. 
Figure 1. Cutting three angles

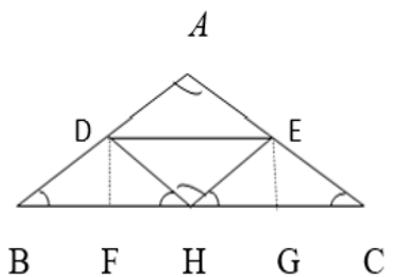

Figure 2. Folding three triangles

During the intervention period, intervention group 1 (IG1) students were taught using visualization techniques that included real-life applications, examples and non-examples, manipulative, GeoGerba software, animation, and multiple representations. The teaching process started by asking students real life application of the topic. This assisted the teacher to get idea about students' previous knowledge. The teacher designs the lessons using visualization techniques and then moves to teaching mathematical concepts using visualization techniques. Then after the teacher exposes students to practice the visualization of mathematical concepts; the teacher assesses students' progress on visualizing with respect to mathematical concepts.

The following examples shows some of the activities which students performed using manipulative (paper-folding).

Prove the sum of the angles of any triangle is $180^{\circ}$.

Check: Showing the measure of the three angles of a triangle is equal to $180^{\circ}$ using alternative approaches.

1. Cutting the three angles (Figure 1).

2. Folding the three small triangles (Figure 2): Fold $A B$ to get the mid-point at $D$ and fold $A C$ to get the mid-point at $E$. From $D$ and $E$ draw perpendicular line to line segment $B C$. Fold in wards $\triangle A D E$ at line segment $D E, \triangle D B F$ at line segment $D F$ and $\triangle \mathrm{CEG}$ at line segment $\mathrm{EG}$. $\angle \mathrm{DBF} \equiv \angle \mathrm{DHF}, \angle \mathrm{ECG} \equiv \angle \mathrm{EHG}, \angle \mathrm{DAE} \equiv \angle \mathrm{DHE}$. The three angles $\angle \mathrm{DHF}+\angle \mathrm{EHG}+\angle \mathrm{DHE}=180^{\circ}$ (since they form a straight line on the base); therefore, $\angle \mathrm{DBF}+\angle \mathrm{ECG}+\angle \mathrm{DAE}=\angle \mathrm{DHF}+\angle \mathrm{EHG}+\angle \mathrm{DHE}=180^{\circ}$.

In intervention group 2 (IG2) problem-based learning approach was used. This teaching approach is a type of teacher-student collaborative approach which consists of the four phases of Polya's problem solving model that are understanding the problem, devising a plan, carrying out the plan and looking back. This was selected since it is specified in the syllabi document. The teaching process started by asking students real life application of the topic. This assisted the teacher to get idea about students' previous knowledge. The teacher arranges the students into heterogeneous ability groups based on their previous performance in mathematics. The teacher poses some problems for the students to solve. The students read the problem again and again in their groups until they understand the problem and identify what is required. After understanding the problem and identifying what is required, the students wrote the problem in their own words. Then the students move to analyze how the problem can be solved. Then after, the students solve the problem and finally check the solution and solution process to generalize the results and apply their knowledge in new problems in groups. The teacher gives class work to each group while encouraging them to follow the heuristics of the model in their discussion. Then after, the teacher appoints any member of the group to present their findings to the entire class while acting as facilitator in a scaffolding manner. Finally, gives an overview of the whole lesson.

The following examples shows some of the activities which students performed using Polya's model of problem-based learning approach.

In a blueprint of a rectangular room, the length is $1 \mathrm{~m}$ more than 3 times the width. Find the dimensions if the perimeter is to be $26 \mathrm{~m}$.

\section{Step-1: Understanding the problem}

Make sure they read the question carefully several times.

We are looking for the length and width of the rectangle. Since length can be written in terms of width, we will let w=width.

Length is $1 \mathrm{~m}$ more than 3 times the width:

$1+3 w=$ length.

Step-2: Devise a plan (Translate)

Perimeter $=2$ (length) +2 (width)

$26=2(1+3 w)+2 w$

Step-3: Carry out the plan (Solve)

$26=2(1+3 w)+2(w)$ 
$26=2+6 w+2 w$ [Remove () by using distribution property].

$26=2+8 w$ [Combine like terms].

$26-2=2+8 w-2$ [Inverse of addition 2 is subtraction 2].

$24=8 \mathrm{w}$

$\frac{24}{8}=\frac{8 w}{8}$ [Inverse of multiplication by 8 is division by 8 ].

$3=\mathrm{w}$

\section{Step-4: Look back (Check and interpret)}

If width is 3 , then length, which is $1 \mathrm{~m}$ more than 3 times the width would have to be 10 . The perimeter of a rectangle with width of $3 \mathrm{~m}$ and length of $10 \mathrm{~m}$ does come out to be $26 \mathrm{~m}$. Thus, the width is $3 \mathrm{~m}$ and the length is $10 \mathrm{~m}$.

In intervention group 3 (IG3) students were taught with visualization techniques-assisted problem-based learning approach. This teaching method is also a type of teacher-student collaborative approach which consists of VT-assisted PBLA. The teacher uses real-life applications, examples- and non-examples-assisted PBLA, GeoGebra-assisted PBLA, animation-assisted PBLA, manipulative-assisted PBLA and multiple representation-assisted PBLA. After doing the integrated approach, the teacher appoints any member of the group to present their findings to the entire class while acting as facilitator in a scaffolding manner by integrating VT-assisted PBLA and other groups engage with the presenter in dialogue to arrive at a consensus and gives an overview of the whole lesson.

The following examples shows some of the activities which students performed using manipulative (paper-folding) in combination with flowchart on problem processes for the problem-based learning.

Objectives: At the end of the lesson students will be able to identify angle-sum theorem.

Content: The sum of the angles of any triangle is $180^{\circ}$.

Previous knowledge: Students used SSS postulate, SAS postulate, and ASA postulate for testing congruency of triangle. They also studied finding area of right triangles.

\section{Procedure:}

Step-1: Arrangement of students into heterogeneous ability groups based on their previous performance in mathematics. The mathematics teacher could help in this area. For instance, the teacher must give to students the application of triangles such as the following:

1. Triangles are used to make rafters in buildings and curved domes, strength in engineering: Triangulation of material, adds strength by eliminating lateral movement;

2. It can be used to stabilize a bridge: In construction to measure out the room and scale size;

3. In light beams to see the distance from light to the target; and

4. To make the roof inclined and the height of the roof in buildings.

The teacher poses some problems for the students to solve e.g. investigate the following questions:

1. Discuss SSS postulate, SAS postulate, and ASA postulate that help you for testing congruency of triangle.

2. Find the relationship among triangles, equilateral triangles, isosceles triangles, right angle triangles, and isosceles rightangle triangles using concept map.

3. Manipulate properties of triangles using paper-folding.

\section{Step-2: Adoption of problem-solving process}

Stage I-Identify the problem: This requires (a) identifying the vertices, interior angles, sum of all angles of a triangle, construction of a triangle, definition of straight angle, and alternate interior angles; (b) identifying the relationship among triangles, equilateral triangles, isosceles triangles, right angle triangles, and isosceles right-angle triangles using concept map; (c) identifying the properties of quadrilaterals using paper-folding; (d) the arithmetic operation involved; and (e) considering substitution.

Stage II-Make assumptions: This requires ability to think critically the way that will satisfy the given condition.

Stage III-Formulate a model: This requires ability to identify a valid approach among many alternatives. In proofing the theorem, one option is feasible namely manipulative (paper folding).

Stage IV-Use the model.

Check: Showing the measure of the three angles of a triangle is equal to 180 .

1. Cutting the three angles (Figure 1).

2. Folding the three small triangles (Figure 2).

Stage $V$-Evaluate the model by observing the results, check the sum of the degree measures of the interior angles of a triangle is equal to $180^{\circ}$. Hence, the whole process will be repeated.

Step-3: The teacher gives class work to each group while encouraging them to follow the heuristics of the model in their discussion.

Step-4: The teacher appoints any member of the group to present their findings to the entire class while acting as facilitator in a scaffolding manner and other groups engage the presenter in dialogue to arrive at a consensus. 
Table 1. Levene's test of equality of error variances

\begin{tabular}{lllll}
\hline Dependent variables & $\mathbf{F}$ & $\mathbf{d f 1}$ & $\mathbf{d f 2}$ & $\mathbf{p}$ \\
\hline Post-confidence & 0.252 & 1 & 94 & \\
\hline Post-csefulness & 2.248 & 1 & 94 & \\
\hline Post-enjoyment & 3.135 & 1 & 94 & 94 \\
\hline Post-engagement & 3.475 & 1 & .137 \\
\hline Post-attitude & 2.489 & 1 & .080 & 94 \\
\hline
\end{tabular}

Table 2. Descriptive statistics of groups for pre-intervention

\begin{tabular}{|c|c|c|c|c|c|}
\hline Components & Group & $\mathbf{N}$ & $M$ & SD & SEM \\
\hline \multirow{4}{*}{ Pre-confidence } & Intervention group 1 (IG1) & 48 & 3.258 & .5442 & .0785 \\
\hline & Intervention group 2 (IG2) & 49 & 3.321 & .5813 & .0830 \\
\hline & Intervention group 3 (IG3) & 48 & 3.188 & .6707 & .0968 \\
\hline & Comparison group (CG) & 47 & 3.327 & .5678 & .0828 \\
\hline \multirow{4}{*}{ Pre-usefulness } & Intervention group 1 (IG1) & 48 & 3.823 & .6851 & .0989 \\
\hline & Intervention group 2 (IG2) & 49 & 3.472 & .8390 & .1199 \\
\hline & Intervention group 3 (IG3) & 48 & 3.474 & .7601 & .1097 \\
\hline & Comparison group (CG) & 47 & 3.617 & .6636 & .0968 \\
\hline \multirow{4}{*}{ Pre-enjoyment } & Intervention group 1 (IG1) & 48 & 3.474 & .5265 & .0760 \\
\hline & Intervention group 2 (IG2) & 49 & 3.819 & .5643 & .0806 \\
\hline & Intervention group 3 (IG3) & 48 & 3.386 & .6391 & .0922 \\
\hline & Comparison group (CG) & 47 & 3.609 & .6275 & .0915 \\
\hline \multirow{4}{*}{ Pre-engagement } & Intervention group 1 (IG1) & 48 & 3.490 & .5935 & .0857 \\
\hline & Intervention group 2 (IG2) & 49 & 3.508 & .5598 & .0800 \\
\hline & Intervention group 3 (IG3) & 48 & 3.469 & .5797 & .0837 \\
\hline & Comparison group (CG) & 47 & 3.497 & .6440 & .0939 \\
\hline \multirow{4}{*}{ Overall pre-intervention } & Intervention group 1 (IG1) & 48 & 3.511 & .4150 & .0599 \\
\hline & Intervention group 2 (IG2) & 49 & 3.530 & .4118 & .0588 \\
\hline & Intervention group 3 (IG3) & 48 & 3.379 & .4696 & .0678 \\
\hline & Comparison group (CG) & 47 & 3.513 & .4632 & .0690 \\
\hline
\end{tabular}

Note. SEM: Standard error mean

Step-5: The teacher gives an overview of the whole lesson leaning on the model. Thereafter the teacher gives assignment to the class. For instance, the teacher may ask the students the value of the angles in different types of triangles and figures associated with triangles.

On the other hand, comparison group (CG) students were taught using the conventional instructional approach. The study lasted for 16 weeks. The content was prepared in line with the curriculum and the same content was taught in each of the four groups. After intervention was completed, students' attitude towards learning mathematics was administered as a postintervention.

\section{Methods of Data Analysis}

The normality of the collected data was checked using skewness of the distribution for the 32 items and the items for each of the components of attitude. The skewness value for each item lied between -2 and +2 (George \& Mallery, 2003). Independence and homogeneity of variance were also checked. Levene's test was used to examine the homogeneity of variances between overall attitude and their components. It is expected to obtain a result which is not significant for dependent variable.

The results in Table 1 showed that there was no violation of homogeneity of variance assumption for all variables $p>0.05$. These indicated that the data was normally distributed. Therefore, it was amendable to used parametric tests for the data analysis. Paired samples t-test, ANOVA and ANCOVA were used in addition to descriptive statistics. Paired sample t-test was employed to compare the mean gain of post-attitude from pre-attitude of each of the intervention groups as well as comparison group. ANOVA was conducted to check for the equivalence of the groups on overall pre-attitude and components of pre-attitude scores. In order to statistically control overall pre-attitude and their components scores, which in turn affects the overall post-attitude and their components to learn mathematics, ANCOVA was employed. Level of significance a of 0.05 was used

\section{RESULTS AND DISCUSSION}

Descriptive statistics for pre-attitude and post-attitude are calculated in order to investigate students' attitude towards learning mathematics and learning mathematics through visualization techniques, problem-based learning approach, visualization techniques-assisted problem-based learning approach, and conventional instructional approach. The attitude scale consisted of four different components. Those are confidence, usefulness, enjoyment, and engagement. Table 2 and Table 3 describe the details of the descriptive statistics of pre- and post-attitude, respectively.

In Table 2, the results of the study showed that components of attitude like confidence, enjoyment and engagement of comparison group (CG) students has a greater mean score followed by intervention group 3 (IG3) students than intervention group 
Table 3. Descriptive statistics of groups for post-intervention

\begin{tabular}{|c|c|c|c|c|c|}
\hline Components & Group & $\mathbf{N}$ & M & SD & SEM \\
\hline \multirow{4}{*}{ Post-confidence } & Intervention group 1 (IG1) & 48 & 3.492 & .7404 & .1069 \\
\hline & Intervention group 2 (IG2) & 49 & 3.365 & .5687 & .0812 \\
\hline & Intervention group 3 (IG3) & 48 & 3.445 & .7270 & .1049 \\
\hline & Comparison group (CG) & 47 & 3.330 & .5963 & .0870 \\
\hline \multirow{4}{*}{ Post-usefulness } & Intervention group 1 (IG1) & 48 & 4.128 & .6366 & .0919 \\
\hline & Intervention group 2 (IG2) & 49 & 3.760 & 1.0504 & .1501 \\
\hline & Intervention group 3 (IG3) & 48 & 4.023 & .8586 & .1239 \\
\hline & Comparison group (CG) & 47 & 3.324 & .8257 & .1204 \\
\hline \multirow{4}{*}{ Post-enjoyment } & Intervention group 1 (IG1) & 48 & 3.805 & .5445 & .0786 \\
\hline & Intervention group 2 (IG2) & 49 & 3.651 & .7873 & .1125 \\
\hline & Intervention group 3 (IG3) & 48 & 3.854 & .7776 & .1122 \\
\hline & Comparison group (CG) & 47 & 3.500 & .6511 & .0950 \\
\hline \multirow{4}{*}{ Post-engagement } & Intervention group 1 (IG1) & 48 & 3.453 & .7121 & .1028 \\
\hline & Intervention group 2 (IG2) & 49 & 3.459 & .6825 & .0975 \\
\hline & Intervention group 3 (IG3) & 48 & 3.674 & .6288 & .0908 \\
\hline & Comparison group (CG) & 47 & 3.282 & .5439 & .0793 \\
\hline \multirow{4}{*}{ Overall post-intervention } & Intervention group 1 (IG1) & 48 & 3.719 & .4900 & .0707 \\
\hline & Intervention group 2 (IG2) & 49 & 3.559 & .5287 & .0755 \\
\hline & Intervention group 3 (IG3) & 48 & 3.749 & .4510 & .0651 \\
\hline & Comparison group (CG) & 47 & 3.359 & .4476 & .0653 \\
\hline
\end{tabular}

Note. M: Mean; SD: Standard deviation; SEM: Standard error mean

Table 4. Paired sample t-test results of intervention group 1 taught with visualization techniques

\begin{tabular}{|c|c|c|c|c|c|c|}
\hline \multirow{2}{*}{ Components } & \multicolumn{3}{|c|}{ Paired differences } & \multirow{2}{*}{$\mathbf{t}$} & \multirow{2}{*}{ df } & \multirow[b]{2}{*}{$\mathbf{p}$} \\
\hline & MD & SD & SEM & & & \\
\hline Pre- \& post-confidence & .2344 & .7218 & .1042 & 2.250 & 47 & .029 \\
\hline Pre- \& post-usefulness & .3047 & .9592 & .1385 & 2.201 & 47 & .033 \\
\hline Pre- \& post-enjoyment & .3307 & .6566 & .0948 & 3.490 & 47 & .001 \\
\hline Pre- \& post-engagement & -.0365 & .8824 & .1274 & -.286 & 47 & .776 \\
\hline Pre- \& post-attitude & .2083 & .5271 & .0761 & 2.738 & 47 & .009 \\
\hline
\end{tabular}

Note. MD: Mean difference; SD: Standard deviation; SEM: Standard error mean

2 (IG2), and intervention group 1 (IG1) students. This indicated that before intervention was given to groups, comparison group (CG) students had better attitude toward learning mathematics than intervention group 2 (IG2), intervention group 1 (IG1), and intervention group 3 (IG3) students, except for usefulness which was higher for intervention group 1 (IG1). Nonetheless, the mean score of each component of attitude towards learning mathematics is greater than $(M=3.00)$ and some of the variations range upto 0.1199 which counteracts to demand further analysis.

The results in Table 3 indicate that the confidence and usefulness components of attitude of intervention group 1 (IG1) student had a greater mean score than intervention group 3 (IG3) students, and followed by intervention group 2 (IG2) students. Whereas enjoyment and engagement components of attitude of intervention group 3 (IG3) student had greater mean score than intervention group 1 (IG1) students and followed by Intervention group 2 (IG2) students. But comparison group (CG) students have the lowest mean score. Across all groups intervention group 3 (IG3) students shown to have a greater mean score than intervention group 1 (IG1) students and followed by intervention group 2 (IG2) students and comparison group (CG), respectively. This indicates that after treatments were given to each group, intervention group 3 (IG3) students manifested a better enjoyment and engagement components of attitude than intervention group 1 (IG1) students who were taught through visualization techniquesassisted problem-based learning approach while intervention group 1 (IG1) students manifested a better confidence and usefulness components of attitudes than intervention group 3 (IG3) students through visualization techniques. In general, all intervention groups students manifested a better component of attitudes than comparison group. In spite of these descriptive results, the mean score of each component of attitude toward learning of mathematics is greater than $(M=3.00)$ and the variations range up-to .1501 which offsets to call further analysis.

Paired sample t-test was employed to compare the mean gain of the pre-attitude with the post-attitude of each of the intervention groups as well as the comparison group. The result for intervention group 1 (G1) is presented in Table 4.

The results in Table 2 and Table 3 showed that the mean scores of both pre-attitude and post-attitude of students were above 3.00 indicating that students seemed to have a better attitude toward learning mathematics and learning mathematics using visualization techniques. Revealed also is that the mean of the pre-attitude ( $M=3.511)$ is smaller than the mean of the post-attitude $(M=3.719)$. The paired sample $t$-test between pre- and post-attitude of students showed that $t(47)=2.738, p=.009$ and this indicates there was significant difference between the mean scores of pre- and post-attitudes of students learning through visualization techniques. This indicates positive contribution of visualization technique towards increasing the attitude of students towards learning mathematics.

Regarding each of the components of the attitude, Table 4 showed that the paired sample t-test value was $t(47)=2.250, p=.029$ for confidence, $t(47)=2.201, p=.033$ for usefulness and $t(47)=3.490, p=.001$ for enjoyment. This indicates that there was a significant mean difference between components of attitude of pre-confidence and post-confidence; pre-usefulness and post-usefulness as 
Table 5. Paired sample t-test results of intervention group 2 taught with problem-based learning approach

\begin{tabular}{|c|c|c|c|c|c|c|}
\hline \multirow{2}{*}{ Components } & \multicolumn{3}{|c|}{ Paired differences } & \multirow{2}{*}{$\mathbf{t}$} & \multirow{2}{*}{ df } & \multirow[b]{2}{*}{$\mathbf{p}$} \\
\hline & MD & SD & SEM & & & \\
\hline Pre- \& post-confidence & .0434 & .7821 & .1117 & .388 & 48 & .700 \\
\hline Pre- \& post-usefulness & .2883 & 1.3361 & .1909 & 1.510 & 48 & .138 \\
\hline Pre- \& post-enjoyment & -.1684 & .7393 & .1056 & -1.594 & 48 & .117 \\
\hline Pre- \& post-engagement & -.0485 & .8052 & .1150 & -.421 & 48 & .675 \\
\hline Pre- \& post-attitude & .0287 & .5333 & .0762 & .377 & 48 & .708 \\
\hline
\end{tabular}

Note. MD: Mean difference; SD: Standard deviation; SEM: Standard error mean

Table 6. Paired sample t-test results of intervention group 3 taught with visualization techniques-assisted problem-based learning

\begin{tabular}{|c|c|c|c|c|c|c|}
\hline \multirow{2}{*}{ Components } & \multicolumn{3}{|c|}{ Paired differences } & \multirow{2}{*}{$\mathbf{t}$} & \multirow{2}{*}{ df } & \multirow{2}{*}{$\mathbf{p}$} \\
\hline & MD & SD & SEM & & & \\
\hline Pre- \& post-confidence & .2573 & .9837 & .1420 & 1.812 & 47 & .076 \\
\hline Pre- \& post-usefulness & .5495 & 1.0190 & .1471 & 3.736 & 47 & .001 \\
\hline Pre- \& post-enjoyment & .4682 & 1.0458 & .1510 & 3.102 & 47 & .003 \\
\hline Pre- \& post-engagement & .2057 & .9126 & .1317 & 1.562 & 47 & .125 \\
\hline Pre- \& post-attitude & .3703 & .6780 & .0979 & 3.784 & 47 & .000 \\
\hline
\end{tabular}

Note. MD: Mean difference; SD: Standard deviation; SEM: Standard error mean

well as pre-enjoyment and post-enjoyment except pre-engagement and post-engagement. That is, the three components of attitude showed significant difference through the use of visualization technique. This confirms there were changes in the mean scores after implementation of visualization techniques. This research finding coincides with the research conducted by Chun and Ming (2015) which indicated that utilization of visualization techniques in the classroom could increase positive attitude as learning enjoyment of students. Moreover, this research finding agrees with the findings of Akinsola and Animashun (2007), Rabab'h and Veloo (2015), and Reimer \& Mayer (2005) who stated that there is a positive relationship between these instructional approaches and students' attitude, and also there is a direct association between attitude and learning mathematics. Whereas the results of the study indicated that there was no significant mean difference between the components of pre-engagement and post-engagement. This might be due to various reasons some of which could be lack of students' experience or they are new to such kinds of instructional approach.

The results in Table 2 and Table 3 indicated that the total means of the pre-attitude $(M=3.530)$ is almost the same as the total means of the post-attitude $(M=3.559)$. This indicates that students in this group seem to have the same attitude toward learning mathematics before and after intervention.

The paired sample t-test between pre- and post-attitude of student shows that $t(48)=.377, p=.708$ which indicates that there was no significant difference between mean scores of pre- and post-attitudes (Table 5). Moreover, there was no significant difference between mean scores of their components. This result shows that PBLA did not bring a significant difference in students' attitude to learn mathematics. This might happen due to a lack of experience, and a lack of attitude to learn mathematics.

Though, literature indicates that PBLA had a positive effect on students' attitude to learn mathematics, Ruhan (2007), Uygun and Tertemiz (2014), and Walker and Lofton (2003) which indicated that visualization techniques and problem-based learning approaches increases students' attitude toward learning of mathematics and retention of subject matters, the results of the study disagrees with these research works. From the aforementioned notes, we see that, such a contending result need to be investigated further to help explore associated predictors of variations.

The researchers tried explore if the result is the same within intervention group 3 of the pre-attitude and post-attitude and their components as shown in Table 6.

In Table 2 and Table 3, the total mean scores of the pre-attitude ( $M=3.379)$ and post attitude $(M=3.749)$ show that students in this group have good attitude towards learning mathematics before and after intervention. The descriptive statistic of post attitude $(M=3.749)$ is greater than that of the pre-attitude $(M=3.379)$. The paired samples t-test of attitude of students between preand post- intervention, shown in Table 6 also reveals that $\mathrm{t}(47)=3.784, \mathrm{p}=.000$ and this indicates there was significant difference between the mean scores of pre- and post-attitudes of students who were taught through visualization techniques-assisted problem-based learning approach

Table 6 also presented the pairwise comparison results for each of the components of attitude, and it indicated that the paired samples t-test value was $t(47)=3.736, p=.001$ for usefulness and $t(47)=3.102, p=.003$ for enjoyment. These indicate that there was a statistically significant mean difference between components of attitude of pre-usefulness and post-usefulness as well as preenjoyment and post-enjoyment. From these we see that two components of attitude showed significant difference while the other two did not, that are confidence and engagement. Though, there was statistically significant difference on confidence through the use of visualization techniques alone (Table 4), but it shown non-significant difference when visualization was used with PBLA. Inspection of the means of pre-confidence $(M=3.188)$ and post-confidence $(M=3.445)$ shows the existence of difference. This shows the existence of improvement on students' confidence in learning mathematics. This research finding coincides the research conducted by Murni et al. (2017) and Septian et al. (2019) which stated that the utilization of GeoGebra-assisted problem-based learning can lead to solving problems and students' attitudes toward mathematics are better.

In Table 2 and Table 3, the results of the study showed that the total mean scores of the pre-attitude $(M=3.351)$ and postattitude ( $M=3.359)$ show that students in this group seem to the same attitude towards learning mathematics when taught using 
Table 7. Paired sample t-test results of comparison group

\begin{tabular}{|c|c|c|c|c|c|c|}
\hline \multirow{2}{*}{ Components } & \multicolumn{3}{|c|}{ Paired differences } & \multirow{2}{*}{$\mathbf{t}$} & \multirow{2}{*}{ df } & \multirow{2}{*}{$\mathbf{p}$} \\
\hline & MD & SD & SEM & & & \\
\hline Pre- \& post-confidence & -.0027 & .7650 & .1116 & -.024 & 46 & .981 \\
\hline Pre- \& post-usefulness & .2931 & .6674 & .1165 & .688 & 46 & .247 \\
\hline Pre- \& post-enjoyment & .1090 & .7579 & .1106 & .986 & 46 & .329 \\
\hline Pre- \& post-engagement & .2154 & .7571 & .1104 & 1.951 & 46 & .057 \\
\hline Pre- \& post-attitude & .1537 & .6065 & .1739 & .796 & 46 & .463 \\
\hline
\end{tabular}

Note. MD: Mean difference; SD: Standard deviation; SEM: Standard error mean

Table 8. ANOVA test on components of pre-attitude and overall pre-attitude towards mathematics

\begin{tabular}{|c|c|c|c|c|c|c|}
\hline Components & & SS & df & MS & $\mathbf{F}$ & $\mathbf{p}$ \\
\hline & Between groups & .615 & 3 & .205 & .582 & .627 \\
\hline \multirow[t]{3}{*}{ Pre-confidence } & Within groups & 66.124 & 188 & .352 & & \\
\hline & Total & 66.738 & 191 & & & \\
\hline & Between groups & 7.770 & 3 & 2.590 & 4.715 & .003 \\
\hline \multirow[t]{3}{*}{ Pre-usefulness } & Within groups & 103.260 & 188 & .549 & & \\
\hline & Total & 111.030 & 191 & & & \\
\hline & Between groups & 5.183 & 3 & 1.728 & 4.946 & .003 \\
\hline \multirow[t]{3}{*}{ Pre-enjoyment } & Within groups & 65.671 & 188 & .349 & & \\
\hline & Total & 70.854 & 191 & & & \\
\hline & Between groups & .039 & 3 & .013 & .037 & .990 \\
\hline \multirow[t]{3}{*}{ Pre-engagement } & Within groups & 66.476 & 188 & .354 & & \\
\hline & Total & 66.515 & 191 & & & \\
\hline & Between groups & 1.115 & 3 & .372 & 1.894 & .132 \\
\hline \multirow[t]{2}{*}{ Pre-attitude } & Within groups & 36.902 & 188 & .196 & & \\
\hline & Total & 38.017 & 191 & & & \\
\hline
\end{tabular}

Note. SS: Sum of the squares; MS: Mean square

Table 9. Post-hoc Tukey HSD tests on components of pre-attitude towards mathematics

\begin{tabular}{|c|c|c|c|c|c|}
\hline Components & (I) Group & (J) Group & MD (I-J) & SEM & $\mathbf{p}$ \\
\hline \multirow{6}{*}{ Pre-usefulness } & \multirow{3}{*}{ Intervention group 1} & Intervention group 2 & .3510 & .1505 & .094 \\
\hline & & Intervention group 3 & .3490 & .1513 & .100 \\
\hline & & Comparison group & -.0946 & .1521 & .925 \\
\hline & \multirow{2}{*}{ Intervention group 2} & Intervention group 3 & -.0020 & .1505 & 1.000 \\
\hline & & Comparison group & $-.4456^{*}$ & .1513 & .019 \\
\hline & Intervention group 3 & Comparison group & $-.4436^{\star}$ & .1521 & .021 \\
\hline \multirow{6}{*}{ Pre-enjoyment } & \multirow{3}{*}{ Intervention group 1} & Intervention group 2 & $-.3449^{\star}$ & .1200 & .023 \\
\hline & & Intervention group 3 & .0885 & .1206 & .883 \\
\hline & & Comparison group & -.1351 & .1213 & .681 \\
\hline & \multirow{2}{*}{ Intervention group 2} & Intervention group 3 & $.4335^{*}$ & .1200 & .002 \\
\hline & & Comparison group & .2098 & .1207 & .307 \\
\hline & Intervention group 3 & Comparison group & -.2236 & .1213 & .256 \\
\hline
\end{tabular}

Note. MD: Mean difference; SEM: Standard error mean; *The mean difference is significant at the 0.05 level

conventional instructional approach. The paired samples t-test of attitude of students between pre- and post- conventional instructional approach, shown in Table 7 also indicated $t(46)=.796, p=.463$ and this shows there was no significant difference between the mean scores of pre- and post-attitudes of students who were taught through conventional instructional approach.

Moreover, the researchers tried to explore if the results were the same for the attitude and the components of attitude across the intervention groups and comparison group. For this purpose, the researchers used one-way analysis of variance (ANOVA) to test the significance of the mean difference among the intervention groups.

In Table 8, the ANOVA results indicated that pre-confidence and pre-engagement components of attitude and the overall attitude did not show statistically significant differences among the intervention groups in learning mathematics. Whereas a statistically significant difference was found among the three intervention groups on pre-usefulness and pre-enjoyment components of attitude with $F(3,188)=4.715, p=.003$ and with $F(3,188)=4.946, p=.003$, respectively. Since the assumption of homogeneity of variances was not violated for the components of attitude, Tukey HSD test was employed to check the pairwise comparison (see Table 1).

In Table 9, post-hoc Tukey HSD test indicate that the intervention group 2 and comparison group; and intervention group 3 (IG3) and comparison group differ significantly on their view toward usefulness of mathematics. Moreover, for enjoyment the intervention group 1 (IG1) and intervention group 2 (IG2); and intervention group 2 (IG2) and intervention group 3 (IG3) shown to differ significantly. This priory variation was considered to check the difference in attitude of the groups after intervention, and the result is presented in Table 10.

In Table 10, the results of the ANCOVA indicated that there was statistically significant difference between the groups in each of the components of attitude except confidence and engagement when the effect of variation during pre-components of attitude 
Table 10. Results of ANCOVA for components of post-attitude and post-overall attitude scores

\begin{tabular}{|c|c|c|c|c|c|c|c|}
\hline Components & Source & Type III SS & df & MS & $\mathbf{F}$ & $\mathbf{p}$ & $\eta^{2}$ \\
\hline \multirow{4}{*}{ Post-confidence } & Corrected model & 2.671 & 4 & .668 & 1.55 & .190 & .032 \\
\hline & Intercept & 48.744 & 1 & 48.744 & 113.09 & .000 & .377 \\
\hline & Pre-confidence & 1.885 & 1 & 1.885 & 4.37 & .038 & .023 \\
\hline & Group & .972 & 3 & .324 & .75 & .523 & .012 \\
\hline \multirow{4}{*}{ Post-usefulness } & Corrected model & 20.255 & 4 & 5.064 & 6.96 & .000 & .130 \\
\hline & Intercept & 79.956 & 1 & 79.956 & 109.94 & .000 & .370 \\
\hline & Pre-usefulness & 2.026 & 1 & 2.026 & 2.79 & .097 & .015 \\
\hline & Group & 19.422 & 3 & 6.474 & 8.90 & .000 & .125 \\
\hline \multirow{4}{*}{ Post-enjoyment } & Corrected model & 7.768 & 4 & 1.942 & 4.15 & .003 & .082 \\
\hline & Intercept & 39.571 & 1 & 39.571 & 84.57 & .000 & .311 \\
\hline & Pre-enjoyment & 4.103 & 1 & 4.103 & 8.77 & .003 & .045 \\
\hline & Group & 5.160 & 3 & 1.720 & 3.67 & .013 & .056 \\
\hline \multirow{4}{*}{ Post-engagement } & Corrected model & 3.198 & 4 & .549 & 1.52 & .143 & .051 \\
\hline & Intercept & 53.020 & 1 & 53.020 & 127.32 & .000 & .405 \\
\hline & Pre-engagement & .510 & 1 & .510 & 1.224 & .270 & .007 \\
\hline & Group & 3.737 & 3 & 1.246 & 2.99 & .032 & .046 \\
\hline \multirow{4}{*}{ Post-attitude } & Corrected model & 7.345 & 4 & 1.836 & 8.44 & .000 & .153 \\
\hline & Intercept & 20.581 & 1 & 20.581 & 94.56 & .000 & .336 \\
\hline & Pre-attitude & 2.779 & 1 & 2.779 & 12.77 & .000 & .064 \\
\hline & Group & 5.547 & 3 & 1.849 & 8.49 & .000 & .120 \\
\hline
\end{tabular}

Note. SS: Sum of the squares; MS: Mean square

were controlled. Moreover, the result of the ANCOVA indicated that there was statistically significant difference between the groups in the overall attitude when the effect of variation during pre-intervention were controlled. This indicated that there was an association among the students' components of post- attitude and post- overall attitude toward mathematics and the instructional methods. The value of $\eta^{2}$ was .120 for students' overall attitude toward mathematics and this corresponds to medium effect size as presented in Cohen (1988). This means only $12 \%$ of the variability in dependent variable was associated with the instructional approach used during intervention. This shows that the instructional methods used had a considerable effect on the post- overall attitude mean of the groups. This result agreed with finding of Akinsola and Animashun (2007), Mohamed and Waheed (2011), Murni et al. (2017), Sirmaci (2010), and Uygun and Tertemiz (2014) who in their previous studies found that students taught using instructional methods used had better attitude to learn mathematics than their counterparts taught with conventional approach.

In general, the results of the study indicated that there was statistically significant difference in the overall attitude between the groups, except for PBLA ( $p=.708)$ and $\mathrm{CIA}(\mathrm{p}=.463)$. PBLA and $\mathrm{CIA}$ did not contribute towards ensuring statistically significant difference on overall attitude and its components. Engagement was also never influenced by the use of any of the interventions as well as comparison group ( $p>.05$ ). Among the instructional approaches VT was found to bring statistically significant difference in the overall attitude and its components except engagement. Also, statistically significant difference was found for VT-assisted PBLA except for confidence and engagement. Though, confidence did not show statistically significant difference when VT with PBLA was employed while it was significant with the use of VT alone, inspection of the means of pre-confidence $(M=3.188)$ and post-confidence $(M=3.445)$ shows the existence of difference. This shows the existence of improvement on students' confidence in learning mathematics.

\section{CONCLUSIONS AND RECOMMENDATIONS}

The purpose of this study was to investigate the effects of visualization and problem-based learning approach on middle school students' attitude. The results showed that there was statistically significant difference between the mean scores of preand post- attitudes of students and each of the components of attitude except for engagement within intervention group 1-taught with visualization techniques.

There was no significant difference between the mean scores of pre- and post-attitudes and their components within intervention group 2-taught with problem-based learning approach.

The literature indicates that PBLA had a positive effect on students' attitude to learn mathematics. In contrast to this, this study shows that PBLA did not bring a significant difference in students' attitude to learn mathematics. This seeks further study.

There was also significant difference between the mean scores of pre-attitudes and post-attitudes of students and for the usefulness and enjoyment components of attitude within intervention group3 taught with visualization techniques-assisted problem-based learning approach except for confidence and engagement.

There was no significant difference between the mean scores of pre- attitudes and post- attitude as well as the all components of attitude of students within comparison group-taught with conventional instructional approach.

Furthermore, there was statistically significant difference on the overall attitude between the mean scores of post- attitudes between groups when the effect of variation during pre-attitude were controlled.

From these the following conclusions were drawn: 
1. Visualization technique as well as visualization technique-assisted PBLA were found to be useful approach to enhance attitude and the components of attitude.

2. The reason why PBLA failed to ensure significant difference, though promoted in the literature, needs further investigation.

3. Engagement was not significantly influenced by any one of the instructional approaches employed, and hence seeks further review.

Based on the conclusions stated in the above and the deviant results obtained with this study, the following recommendations are forwarded:

1. The instructional approaches visualization techniques as well as visualization techniques- assisted problem-based learning approach were significantly contributing towards increasing attitude except for engagement. Hence, it is useful to employ visualization techniques and visualization techniques-assisted problem-based learning approach with amendments to encompass engagement.

2. While problem-based learning approach is promoted in the literature, the result of this study did not support the use of problem-based learning approach to increase attitude. Whether problem-based learning approach seeks issues of design or demands contextual appeal, it is worth conducting further study.

3. The association between instructional approach and engagement, and how best engagement can be promoted through the use of instructional approach also seeks further exploration.

Author contributions: All authors have sufficiently contributed to the study, and agreed with the results and conclusions.

Funding: No funding source is reported for this study.

Declaration of interest: No conflict of interest is declared by authors.

\section{REFERENCES}

Abe, T. O., \& Gbenro, O. S. (2014). A Comparison of students' attitudinal variables towards mathematics between private and public senior secondary schools. Journal of Educational Policy and Entrepreneurial Research, 1(1), 32-39.

Adelson, J. L., \& McCoach, D. B. (2011). Development and psychometric properties of the math and me survey: Measuring third through sixth graders' attitudes toward mathematics. Measurement and Evaluation in Counselling and Development, 44(4), 225247. https://doi.org/10.1177/0748175611418522

Ajayi, K. O., Lawani, A. O., \& Adeyanju, H. I. (2013). Effects of students' attitude and self-concept on achievement in senior secondary school mathematics in Ogun State, Nigeria. Journal of Research in National Development, 9(2), 202-211.

Akinsola, M. K., \& Animasahun, I. A. (2007). The effect of simulation-games environment on students' achievement in and attitudes to mathematics in secondary schools. The Turkish Online Educational Technology, 6(3), 11.

Akinsola, M. K., \& Olowojaiye, F. B. (2008). Teacher instructional methods and student attitudes towards mathematics. International Electronic Journal of Mathematics Education, 3(1), 60-73. https://doi.org/10.29333/iejme/218

Astriani, N., Surya, E., \& Syahputra, E. (2017). The effectiveness of using problem based learning in mathematics problem solving ability for junior high school students. International Journal of Advance Research and Innovative Ideas in Education,3(2), 34413446.

Best, J. W., \& Kahn, J. V. (2006). Research in education. Pearson Education, Inc.

Beswick, K. (2006). The importance of mathematics teachers' beliefs. Australian Mathematics Teacher, 62(4), 17-22.

Chun, Y. L., \& Chen, M. J. (2015). Effect of worked examples using manipulatives on fifth grade learning performance and attitude towards mathematics. Educational Technology and Society,18(1), 264-275.

Cohen, J. (1988). Statistical power analysis for the behavioural sciences. Erlbaum.

Creswell, J. W., \& Plano Clark, V. L. (2011). Designing and conducting mixed methods research. SAGE.

Eleftherios, K., \& Theodosios, Z. (2007). Students' beliefs and attitudes concerning mathematics and their effect on mathematical ability. CERME, 5, 258-267.

Enu, J., Agyman, O. K., \& Nkum, D. (2015). Factors influencing students' mathematics performance in some selected colleges of education in Ghana. International Journal of Education Learning and Development, 3(3), 68-74.

Gangwer, T. (2015). Shifting to visual teaching. https://www.teachthought.com/learning/shifting-visual-teaching/

Ganley, C. M., \& Lubienski, S. T. (2016). Mathematics confidence, interest, and performance: Examining gender patterns and reciprocal relations. Learning and Individual Differences, 47, 182-193. https://doi.org/10.1016/j.lindif.2016.01.002

George, D., \& Mallery, P. (2003). SPSS for windows step by step: A simple guide \& reference 11.0 update. Allyn \& Bacon.

Gregoire, J. (2016). Understanding creativity in mathematics for improving mathematical education. Journal of Cognitive Education \& psychology, 15(1), 24-36. https://doi.org/10.1891/1945-8959.15.1.24

Guy, G. M., Cornick, J., \& Beckford, I. (2015). More than math: On the affective domain in developmental mathematics. International Journal for the Scholarship of Teaching and Learning, 9(2), 7. https://doi.org/10.20429/ijsotl.2015.090207 
Hannula, M. S., Maijala, H., \& Pehkonen, E. (2004). Development of understanding and self-confidence in mathematics; grades 58. In International Group for the Psychology of Mathematics Education, Proceedings of the 28th Conference of the International Group for the Psychology of Mathematics Education (pp 1-24).

Ignacio, N. G., Nieto, L. J., \& Barona, E. G. (2006). The affective domain in mathematics learning. International Electronic Journal of Mathematics Education, 1(1), 16-31. https://doi.org/10.29333/iejme/169

Kupari, P., \& Nissinen, K. (2013). Background factors behind mathematics achievement in Finnish education context: Explanatory models based on TIMSS 1999 and TIMSS 2011 data. IEA CONFERENCE 2013 Proceedings.

Lipnevich, A. A., MacCann, C., Krumm, S., Burrus, J., \& Roberts, R. D. (2011). Mathematics attitudes and mathematics outcomes of US and Belarusian middle school students. Journal of Educational Psychology, 103(1), 105. https://doi.org/10.1037/a0021949

Mata, M. D., Monteiro, V., \& Peixoto, F. (2012). Attitudes towards mathematics: Effects of individual, motivational, and social support factors. Child Development Research, 2012, 1-10. https://doi.org/10.1155/2012/876028

Mazana, M., Montero, C., \& Casmi, R. (2019). Investigating students' attitude towards learning mathematics. International Electronic Journal of Mathematics Education, 14(1), 207-231. https://doi.org/10.29333/iejme/3997

Mensah, J. K., Okyere, M., \& Kuranchie, A. (2013). Student attitude towards mathematics and performance: Does the teacher attitude matter? Journal of Education and Practice, 4(3), 132-139.

MoE. (2011). Grade 7 mathematics. Student textbook. Kuraz International Publisher P.L.C.

Mohamed, L., \& Waheed, H. (2011). Secondary students' attitude towards mathematics in a selected school of Maldives. International Journal of humanities and Social Science, 1(15), 277-281.

Murni, V., Sariyasa, S., \& Ardana, M. (2017. GeoGebra assist discovery learning lodel for problem solving ability \& attitude toward mathematics. Journal of Physics: Conference Series, 895(2017), 012049. https://doi.org/10.1088/1742-6596/895/1/012049

NEAEA. (2016). Ethiopian fifth national learning assessment of grades four and eight students. National Educational Assessment and Examinations Agency.

Ngussa, B. M., \& Mbuti, E. E. (2017). The Influence of humour on learners' attitude and mathematics achievement: A case of secondary schools in Arusha City, Tanzania. Journal of Educational Research, 2(3), 170-181.

Pajares, F., \& Miller, D. (1994). Role of self-efficacy and self-concept beliefs in mathematical problem solving: A path analysis. Journal of Educational Psychology, 86, 193-203. https://doi.org/10.1037/0022-0663.86.2.193

Phonapichat, P., Wongwanich, S., \& Sujiva, S. (2014). An analysis of elementary school students' difficulties in mathematical problem solving. Procedia-Social and Behavioral Sciences, 116, 3169-3174. https://doi.org/10.1016/j.sbspro.2014.01.728

Pierce, R., Stacey, K., \& Barkatsas, A. (2007). A scale for monitoring students' attitudes to learning mathematics with technology. Computers \& Education, 48(2), 285-300. https://doi.org/10.1016/j.compedu.2005.01.006

Rabab'h, B., \& Veloo, A. (2015). Spatial visualization as mediating between mathematics learning strategy \& mathematics achievement among $8^{\text {th }}$ grade students. International Education Studies, 8(5), 1-11. https://doi.org/10.5539/ies.v8n5p1

Reimer, K., \& Mayer, P. S. (2005). Third-graders learn about fractions using virtual manipulatives: a classroom study. The Journal of Computers in Mathematics and Science Teaching, 24(1), 5-25.

Ruhan, O. T. (2007). The effect of problem-based active learning in science education on students' academic achievement, attitude and concept learning. Eurasia Journal of Mathematics, Science and Technology Education, 3(1), 71-81. https://doi.org/10.12973/ ejmste/75375

Saffer, N. (1999). Core subjects and your career. Occupational Outlook Quarterly, 26-40.

Seaton, M., Parker, P., Marsh, H. W., Craven, R. G., \& Yeung, A. S. (2014). The reciprocal relations between self-concept, motivation and achievement: Juxtaposing academic self-concept and achievement goal orientations for mathematics success. Educational Psychology, 34(1), 49-72. https://doi.org/10.1080/01443410.2013.825232

Septian, A., Inayah, S., Suwarman, R., \& Nugraha, R. (2019). GeoGbra-assisted problem based learning to improve mathematical problem-solving ability. In Proceeding of the SEMANTIK Conference of Mathematics Education (pp 67-71). Atlantis Press.

Shadish, W. R., Cook, T. D., \& Campbell, D. T. (2002). Experimental and quasi-experimental designs for generalized causal inference. Houghton Mefflin Company.

Shatri, K., \& Buza, K. (2017). The use of visualization in teaching and learning process for developing critical thinking of students. European Journal of Social Sciences Education and Research, 4(1), 71-74. https://doi.org/10.26417/ejser.v9i1.p71-74

Sirmaci, N. (2010). The relationship between the attitudes towards mathematics and learning styles. Procedia Social and Behavioral Sciences, (9), 644-648. https://doi.org/10.1016/j.sbspro.2010.12.211

Stipek, D. (2002). Motivation to learn: Integrating theory and practice. Allyn and Bacon.

Sullivan, P., \& McDonough, A. (2007). Eliciting positive student motivation for learning mathematics. In J. Watson, \& K. Beswick (Eds.), Proceedings of the 30th Annual Conference of the Mathematics Education Research Group of Australasia (pp. 698-707). Australia.

Syyeda, F. (2016). Understanding attitudes towards mathematics (ATM) using a multimodal modal model: An exploratory case study with secondary school children in England. Cambridge Open-Review Educational Research e-Journal, 3, 32-62.

TGE. (1994). Education and training policy EEP 86. Transitional Government of Ethiopia. 
Uygun, N., \& Tertemiz, N. (2014). Effects of problem-based learning on students attitudes, achievement and retention of Learning in mathematics course. Education and Science, 39(174), 75-90. https://doi.org/10.15390/EB.2014.1975

Walker, J., \& Lofton, S. (2003). Effect of a problem based learning curriculum on students' perceptions of self -directed learning. Issues in Educational Research, 13, 71-100.

Wigfield, A., \& Eccles, J. S. (2000). Expectancy-value theory of achievement motivation. Contemporary Educational Psychology, 25, 68-81. https://doi.org/10.1006/ceps.1999.1015 